\title{
Unusual Clinical Presentations of Cervical or Lumbar Dorsal Ramus Syndrome
}

\author{
Shin Jae Kim¹, Myeong Jin Ko', Young Seok Lee ${ }^{1}$, \\ Seung Won Park ${ }^{1}$, Young Baeg Kim ${ }^{1}$, Chan Chung ${ }^{2}$ \\ ${ }^{I}$ Department of Neurosurgery, College of Medicine, Chung-Ang University, Seoul, \\ ${ }^{2}$ Department of Neurosurgery, College of Medicine, Dongguk University, Gyoungju, Korea
}

Objective: Patients with cervical (CDRS) or lumbar dorsal ramus syndrome (LDRS) are characterized by neck or low back pain with referred pain to upper or lower extremities. However, we experienced some CDRS or LDRS patients with unusual motor or bladder symptoms. We analyzed and reviewed literatures on the unusual symptoms identified in patients with CDRS or LDRS.

Methods: This study included patients with unusual symptoms and no disorders of spine and central nervous system, a total of 206 CDRS/LDRS patients over the past 3 years. We diagnosed by using double diagnostic blocks for medial branches of dorsal rami of cervical or lumbar spine with $1 \%$ lidocaine or $0.5 \%$ bupivacaine for each block with an interval of more than 1 week between the blocks. Greater than $80 \%$ reduction of the symptoms, including unusual symptoms, was considered as a positive response. The patients with a positive response were treated with radiofrequencyneurotomy.

Results: The number of patients diagnosed with CDRS and LDRS was 86 and 120, respectively. Nine patients (10.5\%) in the CDRS group had unusual symptoms, including 4 patients with motor weakness of the arm, 3 patients with tremors, and rotatory torticollis in 2 patients. Ten patients (8.3\%) in the LDRS group showed unusual symptoms, including 7 patients with motor weakness of leg, 2 patients with leg tremor, and urinary incontinence in 1 patient. All the unusual symptoms combined with CDRS or LDRS were resolved after treatment.

Conclusion: It seems that the clinical presentationssuch as motor weakness, tremor, urinary incontinence without any other etiologic origin need to be checked for unusual symptoms of CDRS or LDRS.

Key Words: Spinal nerves $\cdot$ Low back pain $\cdot$ Neck pain $\cdot$ Paralysis $\cdot$ Urinary incontinence $\cdot$ Tremor

\section{INTRODUCTION}

Dorsal ramus syndrome (DRS) refers to a variety of symptoms caused by dorsal ramus irritation ${ }^{2,4,24,27)}$. Any abnormality of zygapophysial joint such as subluxation, degenerative changes, osteophytes, hypertrophy of ligament or joint capsule, and fracture can irritate the common dorsal ramus and medial branch, and irritation of dorsal ramuscan cause symp-

- Received: April 20, 2014 - Revised: May 19, 2014

- Accepted: May 21, 2014

Corresponding Author: Seung Won Park, MD, PhD

Deparment of Neurosurgery, Chung-Ang University Hospital, 102 Heukseong-ro, Dongjak-gu, Seoul 156-755, Korea

Tel: +82-2-6299-3190, Fax: +82-2-821-8409

E-mail: nspsw@cau.ac.kr

(This is an Open Access article distributed under the terms of the Creative Commons Attribution Non-Commercial License (http://creativecommons.org/ licenses/by-nc/3.0/) which permits unrestricted non-commercial use, distribution, and reproduction in any medium, provided the original work is properly cited. toms including chronic pain of the cervical or lumbar spine ${ }^{11,24,27}$. In the cervical spine, DRS is known to cause headache, posterior neck pain and referred pain of upper limb $b^{2,6,21)}$, and in the lumbar spine, it can commonly cause lumbar back pain or referred pain of lower limb $b^{3,4,19,25,27)}$. The DRS that occur in cervical and lumbar spine are called Cervical Dorsal Ramus Syndrome (CDRS) ${ }^{6}$ and Lumbar Dorsal Ramus Syndrome (LDRS), respectively. They are usually diagnosed with double diagnostic blocks (DB) and treated with radiofrequency neurotomy (RFN) $4,6,19,21,24)$. We found that DB and RFN improved patients with unusual symptoms such as motor weakness, spasticity, tremor, and bladder symptom in addition to the typical clinical symptoms of patients diagnosed with CDRS and LDRS ${ }^{1,5)}$. But we have not been able to find any other cause for these unusual symptoms. When we fail to find the cause of these unusual symptoms, the treatment must therefore also be difficult. When it is determined these symptoms are caused by the DRS, proper treatment of the symptoms seems to be of great help. We analyzed the clinical characteristics of unusual symptoms seen 
in patients with CDRS and LDRS and tried to suggest their relevant mechanisms.

\section{MATERIALS AND METHODS}

\section{Patients}

A population of 86 CDRS patients diagnosed with cervical DB results who were complaining of headache, posterior neck pain, and upper extremity pain, and 120 LDRS patients confirmed by the results of lumbar DB, who were complaining of back pain and referred pain of lower limb were investigated retrospectively from January 2010 to December 2012.

All patients underwent magnetic resonance imaging (MRI) and neurophysiological tests. Abnormal findings associated with the symptoms were not observed in the results and received RFN if the diagnosis of CDRS or LDRS was confirmed by positive responses in the double DB.

\section{Diagnostic Block (DB)}

DB was performed 2 times at intervals of more than a week (since the time the original symptoms returned) for the diagnosis of DRS. The C3-7 or L4-S1 levels at the symptom side were injected per level with $1 \%$ lidocaine or $0.5 \%$ bupivacaine $0.5 \mathrm{cc}$. 1) If the degree of symptom improvement after double DB was more than $80 \%$, and 2) the time it took for symptoms to be improved by bupivacaine had a difference of at least 3 hours or more than the time by lidocaine, the case was determined to be a positive response. In the anteroposterior (AP) fluoroscopic view of the cervical spine, the target point was set to be located in the dented waist portion of articular pillar and in the lateral fluoroscopic view, located in the center of the articular pillar. The target point of the lumbar spine was set between superior articular process and transverse process.

\section{Radiofrequency Neurotomy (RFN)}

We performed RFN with a radiofrequency generator (Cosman RFG-1B, Cosman Medical, Inc., Burlington, MA, USA) and
SMK-C10 cannula with a $5 \mathrm{~mm}$ exposed tip (Cosman Medical, Inc., Burlington, MA, USA) under biplane fluoroscope. A radiofrequency lesioning was made at $90^{\circ} \mathrm{C}$ for 60 seconds. In the cervical spine, cannula inserted obliquely for target point's positioning parallel to the cervical medial branches and the target point of AP fluoroscopic view was set at the lateral margin of waist portion of articular pillar, and the target point of lateral fluoroscopic view was adjusted so that the exposed tip was placed on the center of articular pillar ${ }^{21)}$. In the lumbar spine, the target point was set between the superior articular process and transverse process of lumbar facet joints and then lesioning was conducted by electrode inserted obliquely ${ }^{19)}$.

\section{Evaluation of Outcome}

The patients on whom DB and then RFN were conducted were to write about the change of symptoms every 30 minutes so that degree of symptoms improvement (\%) and duration of symptoms improvement (minutes) were evaluated. The severity of symptoms was set that symptoms before surgery were 10 points and to be written from 10 points with no improvement in symptoms after treatment to zero without symptoms completely.

\section{RESULTS}

Male to female ratio of CDRS group was 1:2.1 (28:58) and the mean age was $49.1 \pm 11.3$ years. Male to female ratio of LDRS group was 1:1.6 (46:74) and the mean age was 56.8 \pm 14.9 years. There were 9 CDRS patients with unusual symptoms $(10.5 \%)$ and male to female ratio and mean age were 1:2 (3:6), $49.3 \pm 13.1$ years, respectively. There were 4 patients with motor paralysis, 3 patients with upper extremity tremor, and 2 patients complaining of rotatory spasmodic torticollis. There were 10 LDRS patients with unusual symptoms (8.3\%) and male to female ratio and mean age were 1:1 (5:5), 64.2 \pm 12.4 years, respectively. There were 7 patients with motor paralysis of the lower extremities, 2 patients with spasms of the lower extremities, and 1 patient complaining of urinary incontinence (Table 1). While a mean duration of pain in patients with unusual symptoms was of $8.6 \pm 4.6$ weeks in CDRS

Table 1. Cenvical (CDRS) and lumbar dorsal ramus syndrome (LDRS) patients confirmed with diagnostic block

\begin{tabular}{lll}
\hline \hline & \multicolumn{1}{c}{ CDRS } & \multicolumn{1}{c}{ LDRS } \\
\hline Male : Female & $28: 58$ & $46: 74$ \\
Age (years) & $46.1 \pm 11.3$ & $56.8 \pm 14.9$ \\
Unusual symptoms (number) & Motor weakness (4) & Motor weakness (7) \\
& Tremor (3) & Tremor (2) \\
& Rotatory spasmodic torticollis (2) & Urinary incontinence (1) \\
\hline
\end{tabular}


Table 2. Cervical dorsal ramus syndrome patients with unusual symptoms

\begin{tabular}{|c|c|c|c|c|}
\hline Number & $\begin{array}{l}\text { Age } \\
\text { (years) }\end{array}$ & Sex & Typical symptom; duration & Unusual symptoms; duration \\
\hline 1 & 52 & Female & $\begin{array}{l}\text { Posterior neck pain with right shoulder pain; } \\
12 \text { weeks }\end{array}$ & Right upper extremity tremor; 2 weeks \\
\hline 2 & 31 & Male & $\begin{array}{l}\text { Posterior neck pain with both shoulder pain, right side } \\
\text { headache; } 6 \text { weeks }\end{array}$ & Rotatory spasmodic \\
\hline 3 & 74 & Female & $\begin{array}{l}\text { Posterior neck pain with both upper arm pain; } \\
4 \text { weeks }\end{array}$ & $\begin{array}{l}\text { Weakness of both shoulder abduction (motor grade } \\
I M_{i} 1 \text { week }\end{array}$ \\
\hline 4 & 50 & Female & $\begin{array}{l}\text { Posterior neck pain with right shoulder pain, bilateral } \\
\text { headache; } 18 \text { weeks }\end{array}$ & $\begin{array}{l}\text { Weakness of right shoulder abduction (motor grade } \\
\text { IM; } 1 \text { week }\end{array}$ \\
\hline 5 & 63 & Female & Posterior neck pain with left upper arm pain; 5 weeks & Rotatory spasmodic torticollis to left side; 2 weeks \\
\hline 6 & 50 & Male & Right upper arm \& forearm pain; 4 weeks & $\begin{array}{l}\text { Weakness of right wrist extension \& grasping } \\
\text { (motor grade IM); 2weeks }\end{array}$ \\
\hline 7 & 28 & Female & Posterior neck pain with right shoulder pain; 9 weeks & Right hand tremor; 4 weeks \\
\hline 8 & 61 & Female & $\begin{array}{l}\text { Posterior neck pain with left upper arm \& forearm pain; } \\
8 \text { weeks }\end{array}$ & ; Left forearm tremor; 3 weeks \\
\hline 9 & 53 & Male & $\begin{array}{l}\text { Posterior neck pain with right upper arm pain; } \\
11 \text { weeks }\end{array}$ & $\begin{array}{l}\text { Weakness of right shoulder abduction \& elbow flexion } \\
\text { (motor grade } \mathrm{M} \text {; } 2 \text { weeks }\end{array}$ \\
\hline
\end{tabular}

group and 7.2 \pm 3.6 weeks in LDRS group. Degree of pain was severe enough for patients to feel uncomfortable during their daily life. The duration of unusual symptoms was 2.3 \pm 1.1 in the CDRS group and 2.1 \pm 1.0 weeks in the LDRS group. Among the 4 patients with motor paralysis of upper extremities, 2 patients showed shoulder abduction weakness grade IV, 1 patient shoulder abduction and elbow flexion grade IV, and 1 patient wrist extension and grasping power grade IV (Table 2). These motor symptoms of all the 4 patients receiving DB and then RFN improved to grade V. In 4 of 7 patients, motor paralysis of lower extremities had a hip flexion with the motor grade IV, 1 patient showed hip flexion and knee extension motor grade IV, 1 patient knee extension motor grade IV, and1 patient hip flexion and knee extension motor grades IV and III respectively (Table 3). All the motor symptoms of legs were improved to grade $\mathrm{V}$ after RFN. All the other unusual symptoms in CDRS group, tremor and torticollis, or in LDRS group, muscle spasm and urinary incontinence, were also improved completely after RFN.

\section{DISCUSSION}

DRS is needed to differentiate diseases such as myofacial pain syndrome, degenerative disc disease, and facet joint syndrome and long-term treatment outcome as well as the possibility of spontaneous regression is known to be low, ${ }^{4,19,26}$. To confirm the diagnosis 1) specific clinical symptoms (headache, posterior neck pain, and referred pain to upper extremity for CDRS and back pain or referred pain to lower extremity for LDRS), 2) radiologic examinations showed no specific lesions associated with the symptoms, and 3) positive response to DB must be satisfied ${ }^{4,24)}$. Treatment is done first with non-invasive therapy, medication and physical therapy, and if there is no improvement, perform invasive treatment using variable methods of percutaneous rhyzolysis ${ }^{22)}$, and $\mathrm{RFN}^{4,6,16,17,19,21,27 \text {, }}$ etc. Many studies have done on the effects of RFN, and we are usually performing RFN to treat DRS. The initial clues we hypothesized the unusual symptoms might be related with DRS were that they appeared at the same side of usual symptoms of DRS and were effectively improved with DB and RFN. According to several studies, chronic nociceptive stimuli in humans cause cortical relay which is known to reduce the activity of muscles $9,10,12,20)$. These studies suggested that inhibition of nociceptive pathway is important to enhance motor restoration. Within the unusual symptoms of this study, the motor weakness of upper or lower extremities seems to be explained by this theory. In other words, pain induced by CDRS or LDRS causes motor inhibition, and pain relief through RFN would release this nociceptive-induced motor inhibition and improve motor function. When hyperosmolar sodium chloride is injected around the nerve, spasms of distant muscles can occur ${ }^{7,18)}$. Mooney and Robertson ${ }^{18)}$ identified injection in the spinal facet joint as inducing the reflex spasm in the hamstring muscles. In view of these theories, the muscle spasm observed in our study would be caused by irritation of the 
Table 3. Lumbar dorsal ramus syndrome patients with unusual symptoms

\begin{tabular}{|c|c|c|c|c|}
\hline Number & $\begin{array}{l}\text { Age } \\
\text { (years) }\end{array}$ & Sex & Typical symptoms; duration & Unusual symptoms; duration \\
\hline 1 & 43 & Male & Lower back pain with right buttock pain; 12 weeks & Weakness of right hip flexion (motor grade $\mathrm{M}$; 1 week \\
\hline 2 & 70 & Male & Lower back pain with both buttock pain; 4 weeks & Urinary incontinence; 2 weeks \\
\hline 3 & 51 & Female & $\begin{array}{l}\text { Lower back pain with left buttock and thigh pain; } \\
6 \text { weeks }\end{array}$ & $\begin{array}{l}\text { Weakness of left hip flexion and knee extension } \\
\text { (motor grade IV); } 3 \text { weeks }\end{array}$ \\
\hline 4 & 74 & Female & $\begin{array}{l}\text { Lower back pain with both buttock and thigh pain; } \\
14 \text { weeks }\end{array}$ & $\begin{array}{l}\text { Weakness of both hip flexion (motor grade IV; } \\
1 \text { week }\end{array}$ \\
\hline 5 & 66 & Male & Lower back pain with both buttock pain; 5 weeks & $\begin{array}{l}\text { Weakness of right hip flexion (motor grade IM); } \\
2 \text { weeks }\end{array}$ \\
\hline 6 & 50 & Female & Lower back pain with left buttock pain; 4 weeks & Left leg tremor; 2 weeks \\
\hline 7 & 77 & Female & Lower back pain with right buttock pain; 5 weeks & $\begin{array}{l}\text { Weakness of right hip flexion (motor grade IV); } \\
4 \text { weeks }\end{array}$ \\
\hline 8 & 58 & Male & $\begin{array}{l}\text { Lower back pain with left buttock, thigh, and knee } \\
\text { pain; } 8 \text { weeks }\end{array}$ & $\begin{array}{l}\text { Weakness of left knee extension (motor grade IM); } \\
3 \text { weeks }\end{array}$ \\
\hline 9 & 64 & Male & $\begin{array}{l}\text { Lower back pain with left buttock and thigh pain; } \\
10 \text { weeks }\end{array}$ & Left leg tremor; 2 weeks \\
\hline 10 & 72 & Female & $\begin{array}{l}\text { Lower back pain with right thigh and knee pain; } \\
4 \text { weeks }\end{array}$ & $\begin{array}{l}\text { Weakness of right hip flexion (motor grade IV and } \\
\text { knee extension (motor grade III); } 1 \text { week }\end{array}$ \\
\hline
\end{tabular}

facet joint or dorsal ramus. In addition, one of the effective treatments for spasmodic torticollis is selective peripheral denervation ${ }^{1,5)}$ for medial branch of cervical dorsal rami, which can be similar cases improving muscle spasm by reducing sensory input. The pathophysiology of the torticollis combined with CDRS seems to be explained with this mechanism. Movement disorders such as tremors are usually caused by dysfunction of the extrapyramidal system, but may occasionally be caused by peripheral injury ${ }^{15,23}$. Joseph Jankovic and Chris van der linden ${ }^{15)}$ reported that 15 people of a total 28 patients with movement disorders (65\%) had abnormal involuntary movement induced by peripheral trauma. Wilfrid Janig and Ralf Baron ${ }^{14)}$ reported that tremors were observed in approximately $50 \%$ of complex regional pain syndrome patients and these motor changes could be induced by continuous nociceptive input. In addition, they reported the motor changes disappeared through sympathetic blocks. It is thought that the tremors shown in our study might also relate with persistent uncontrolled pain. Hata T. et al. ${ }^{13)}$ reported that pain could reduce the tone of the sympathetic nervous system in experiments on animals. In addition, S.M. Eisenstein et al. ${ }^{8)}$ identified 12 patients with low back pain and urinary incontinence receiving surgical treatment for decreasing of lower back pain. And they also reported improvement of urinary incontinence in 10 patients. According to this theory, the improvement of urinary incontinence by $\mathrm{DB}$ and RFN in our study seemed to be related with reduction of sympathetic tone.
According to our data, on average, five weeks later from the time CDRS or LDRS pain symptoms developed, unusual symptoms tended to occur. This suggests that unusual symptoms are more likely secondary symptoms induced by persistent pain rather than the direct and typical symptoms of CDRS or LDRS. Even though, to the best of our knowledge, there has not been any report trying to explain the unusual symptoms as secondary results of DRS, there are some limitations in our study. Patients evaluated in our study were not those who started with the unusual symptoms but those who noticed to have unusual symptoms in the patients diagnosed as CDRS or LDRS. Therefore, our data could not represent the definitive information about the incidence or pathophysiology of the unusual symptoms. There is also limitation due to the small sample size. There can be unusual symptoms with unrevealed causes other than CDRS or LDRS, but it is difficult to estimate the more complex clues in this study. In order to overcome these problems, a survey of large number of patients with unexplained unusual symptoms in addition to the typical DRS symptoms should be considered.

\section{CONCLUSION}

This study shows that some of the unexplained motor and bladder symptoms can be caused by CDRS or LDRS, which can be resolved successfully by RFN. 


\section{REFERENCES}

1. Bertrand CM: Selective peripheral denervation for spasmodic torticollis: surgical technique, results, and observations in 260 cases. Surg Neurol 40:96-103, 1993

2. Bogduk N: The clinical anatomy of the cervical dorsal rami. Spine 7:319-330, 1982

3. Bogduk N: Lumbar dorsal ramus syndrome. Med J Aust 2:537541, 1980

4. Bogduk N, Long DM: Percutaneous lumbar medial branch neurotomy: a modification of facet denervation. Spine 5:193-200, 1980

5. Braun V, Richter HP: Selective peripheral denervation for the treatment of spasmodic torticollis. Neurosurgery 35:58-63, 1994

6. Cho TG, Hwang SN, Park SW, Nam TK, Hong HJ, Kim YB: Percutaneous Radiofrequency Facet Rhizotomy for Cervical Dorsal Ramus Syndrome. J Korean Neurosurg Soc 40:419-422, 2006

7. Cobb CR, Urban RT, Luekens CA, Bagg RJ: Electrical activity in muscle pain. Am J Phys Med Rehabil 54:80-87, 1975

8. Eisenstein S, Engelbrecht D, El Masry W: Low back pain and urinary incontinence: a hypothetical relationship. Spine 19:11481152, 1994

9. Falla D, Andersen H, Danneskiold-Samsøe B, Arendt-Nielsen L, Farina D: Adaptations of upper trapezius muscle activity during sustained contractions in women with fibromyalgia. J Electromyogr Kinesiol 20:457-464, 2010

10. Farina D, Arendt-Nielsen L, Graven-Nielsen T: Experimental muscle pain decreases voluntary EMG activity but does not affect the muscle potential evoked by transcutaneous electrical stimulation. Neurophysiol Clin 116:1558-1565, 2005

11. Fortin JD: Thoracolumbar Syndrome in athletes. Pain Physician 6:373-376, 2003

12. Graven-Nielsen T, Svensson P, Arendt-Nielsen L: Effects of experimental muscle pain on muscle activity and co-ordination during static and dynamic motor function. Electroencephal Clin Neurophysiol 105:156-164, 1997

13. Hata T, Kita T, Itoh E, Kawabata A: The relationship of hyperalgesia in SART (repeated cold)stressed animals to the autonomic nervous system. J Auton Pharmacol 8:45-52, 1988
14. Jänig W, Baron R: Complex regional pain syndrome: mystery explained ? Lancet Neurol 2:687-697, 2003

15. Jankovic J, Van der Linden C: Dystonia and tremor induced by peripheral trauma: predisposing factors. J Neurol Neurosurg Psychiatry 51:1512-1519, 1988

16. Jun YH, Park JY, Kim SD, Kim SH, Lim DJ, Chung HS: Clinical efficacy of radiofrequency cervical zygapophyseal neurotomy in patients with chronic cervicogenic headache. Kor J Spine 2:257261, 2005

17. Lord SM, Barnsley L, Wallis BJ, McDonald GJ, Bogduk N: Percutaneous radio-frequency neurotomy for chronic cervical zygapophyseal-joint pain. N Engl J Med 335:1721-1726, 1996

18. Mooney V, Robertson J: The facet syndrome. Clin Orthop 115: 149-157, 1976

19. Nam TG, Park SW: Lumbar dorsal ramus syndrome: management with radiofrequency facet rhizotomy. J Korean Neurosurg Soc 34:319-324, 2003

20. Nijs J, Daenen L, Cras P, Struyf F, Roussel N, Oostendorp RA: Nociception affects motor output: a review on sensory-motor interaction with focus on clinical implications. Clin JPain 28: 175-181, 2012

21. Park SW, Park YS, Nam TK, Cho T-G: The effect of radiofrequency neurotomy of lower cervical medial branches on cervicogenic headache. J Korean Neurosurg Soc 50:507-511, 2011

22. Rees W: Multiple bilateral subcutaneous rhizolysis of segmental nerves in the treatment of the intervertebral disc syndrome. Ann Gen Pract 26:392, 1971

23. Schott G: Induction of involuntary movements by peripheral trauma: an analogy with causalgia. The Lancet 328:712-716, 1986

24. Shao Z, Chen Z, Zhou L, Jin A, Li Q: Spinal dorsal ramus syndrome. Chin Med J 109:317, 1996

25. Sihvonen T, Lindgren KA, Airaksinen O, Leino E, Partanen J, Hänninen O: Dorsal ramus irritation associated with recurrent low back pain and its relief with local anesthetic or training therapy. J Spinal Disord Tech 8:8-14, 1995

26. Von Korff M: Studying the natural history of back pain. Spine 19:2041S-2046S, 1994

27. Zhou L, Schneck CD, Shao Z: The Anatomy of Dorsal Ramus Nerves and Its Implications in Lower Back Pain. Neurosci Med 3:192-201, 2012 